\title{
UNGKAPAN BERIMPLIKATUR SEBAGAI STRATEGI KESOPANAN DALAM WARKAH KOLEKSI PENDETA ZA'BA
}

\author{
Implicature As Politeness Strategies in Za'ba's Personal Letters \\ Yusniza Yaakub ${ }^{1}$ \\ yusniza@uum.edu.my
}

Noriah Mohamed ${ }^{2}$

noriahm@usm.my

Universiti Utara Malaysia ${ }^{1}$

Universiti Sains Malaysia ${ }^{2}$

\begin{abstract}
ABSTRAK
Masyarakat Melayu digambarkan sebagai manusia yang mempunyai budaya yang halus, sopan santun, amat mementingkan adab ketika berkomunikasi, enggan menunjukkan sikap biadab serta memanfaatkan kiasan dan perumpamaan sebagai pegangan dalam budaya mereka. Dalam keadaan tertentu, mereka menggunakan ucapan yang berimplikatur kerana lebih memberikan kesan kepada khalayak. Implikatur sebagai satu cabang pragmatik mengambil kira hubungan dengan budaya dan masyarakat. Dengan menggunakan huraian implikatur Grice (1975) dan disesuaikan mengikut huraian Asmah (1992) tentang ungkapan tidak langsung (indirectness speech), kajian ini akan meneliti ungkapan berimplikatur dalam warkah koleksi peribadi Za'ba sebagai strategi kesopanan berbahasa. Warkah-warkah ini dipilih kerana ia merupakan satu warisan sejarah yang tidak ternilai harganya daripada seorang ikon besar dalam dunia Melayu yang terkenal dengan kesarjanaannya. Dapatan kajian dapat menyumbang kepada panduan menggunakan ungkapan berimplikatur dalam tradisi penulisan surat-menyurat. Hasil kajian menunjukkan Za'ba banyak menggunakan implikatur dalam penulisan warkah peribadi beliau.
\end{abstract}

Kata Kunci: implikatur; strategi kesopanan berbahasa; ungkapan tidak berterus terang; warkah koleksi peribadi Za'ba.

\begin{abstract}
The Malay community is described as a cultured, polite, full of humanistic manners, highly regarded manners while communicating, refusing to behave ritually and use figurative speech and parables as a stance in their culture. In some cases, they use indirectness speeches as they affect the audience. Implicature as a pragmatic aspect takes into account the relationship with culture and society. Using the implicative description of Grice (1975) and adapted according to the implicature of Asmah (1992) on indirectness speech, this study examined the personal collection of Za'ba as politeness strategies in his writing. These data were chosen because it is a priceless historical heritage of a well-known icon in the Malay world for his scholarship. The findings of this study can contribute to the guidance of using a coherent expression in the tradition of letter writing. The finding shows that Za'ba used a lot of implicatures in his writing.
\end{abstract}

Keywords: implicature; politeness strategies; indirectness speech; Za'ba's personal letters collection. 


\section{PENDAHULUAN}

Kajian ini membincangkan aspek implikatur sebagai strategi kesopanan dalam warkah koleksi peribadi Za'ba. Huraian aspek ini menggunakan huraian yang dicadangkan oleh Grice (1975) dan disesuaikan oleh Asmah Haji Omar (1992) berdasarkan konteks masyarakat dan budaya Melayu, iaitu ungkapan tidak langsung yang merangkumi beating around the bush atau $B A B$ (selepas ini berbelit-belit), kiasan, berlawanan dan orang perantaraan. Nor Hashimah (1992), menjelaskan bahawa implikatur merujuk mesej tersirat yang digunakan oleh penutur dalam sesuatu peristiwa komunikasi. Mesej yang diterima ini merupakan sesuatu perkara yang dirumuskan daripada perkara yang diperkatakan.

Horn (2004) telah menghuraikan implikatur sebagai, "a component of speaker meaning that constitutes the aspect of what is meant in a speaker utterance without being part of what is said. What speaker intends to communicate is characteristically far richer than what she said express..." (p.3). Penyataan beliau ini dapat disimpulkan dengan maksud bahawa implikatur ialah komponen yang hadir dalam pertuturan seseorang yang maksud atau makna yang diimplikasikan oleh seseorang penutur itu berbeza dengan apa yang dikatakannya.

Searle (1975) pula menyatakan bahawa implikatur juga dikenali sebagai indirect speech act iaitu pertuturan yang dinyatakan secara tidak berterus terang. Dalam membicarakan mengenai implikatur, maksud sesuatu yang tersirat itu sering dikaitkan dengan konteks dan maknanya boleh ditafsir sekiranya kita memahami situasi dan keadaan konteks tersebut. Secara khususnya, untuk mendapatkan maksud tersirat, pendengar perlu mempunyai pengetahuan, pengalaman, serta faham akan konteks yang terjadi pada waktu tersebut (Fatin Rabiha Abdul Kadir \& Zaitul Azma Hamzah (2017).

Selaras dengan sifat orang Melayu yang terkenal dengan kesopanan bahasanya, ada kalanya sesuatu yang hendak disampaikan itu tidak seperti yang diucapkan. Begitu juga dalam penulisan warkah terdahulu. Ada perkara yang disampaikan tidak dinyatakan dengan jelas dengan tujuan menjaga hati dan perasaan pembacanya di samping menonjolkan kesopanan berbahasa. Sara Beden \& Indirawati Zahid (2015) berpandangan bahawa kesopanan berbahasa bukan sahaja penting dan dititikberatkan dalam lisan, malah dalam bentuk penulisan seperti karya sastera. Menurut Nazri Atoh \& Zubir Idris. (2013), percakapan yang digunakan oleh masyarakat Melayu adalah berteraskan agama Islam yang menyuruh kita supaya mengungkapkan sesuatu dengan baik dan sopan. Menurut perspektif Islam, perilaku kesopanan dapat dihuraikan dalam pelbagai aspek seperti kesopanan berbahasa dan kesopanan tingkah laku.

Asmah $\mathrm{Hj}$. Omar (2002) mendefinisikan kesopanan berbahasa sebagai penggunaan bahasa yang berpaksikan kepada peraturan tertentu yang pada amnya ada tiga jenis peraturan penggunaan bahasa, iaitu peraturan linguistik, sosiolinguistik dan pragmatik. Beliau juga pernah mengklasifikasikan kesopanan berbahasa kepada dua aspek; kesopanan asas dan kesopanan berkendala. Menurut beliau, kesopanan asas ialah kesopanan yang telah sedia wujud dalam sesebuah komuniti masyarakat, manakala kesopanan berkendala pula ialah usaha-usaha tertentu yang perlu dilakukan oleh anggota masyarakat dalam berkomunikasi antara satu sama lain dengan memberi perhatian kepada kendalakendala tertentu (Asmah Hj. Omar, 1992). Kendala-kendala ini pula merangkumi faktor siapa bercakap dengan siapa, di mana, mengapa dan bagaimana (who speaks what to whom, where, why and how) seperti yang telah dibincangkan oleh Hymes (1977). Bagi realisasikan faktor-faktor di atas, kita memerlukan strategi-strategi tertentu agar mesej yang disampaikan dapat diterima oleh pendengar, seterusnya mengekalkan konteks kesopanan berbahasa.

Rohaidah Mahshudi, Ahmad Mahmood Musanif, Adi Yasran Abdul Aziz \& Hasnah Mohamad (2013) menyatakan bahawa strategi komunikasi mempunyai kaitan dengan strategi kesopanan, walaupun strategi kesopanan ini bukan berlaku pada keseluruhan strategi komunikasi. Strategi yang dapat memperlihatkan kesopanan lazimnya ditandai dengan kesopanan berdasarkan tingkah laku dan tutur kata yang sopan. Selain itu, Norazlina Mohd. Kiram \& Raja Masittah (2012) telah menghuraikan bahawa kesopanan berbahasa penting sebagai medium dalam membentuk keperibadian dan keharmonian dalam kehidupan bermasyarakat. Dengan berlaku sopan, seseorang itu dapat mengelakkan pendengar daripada merasa gusar, marah dan rasa tersinggung. 
Kajian ini diharapkan dapat menambahkan pengetahuan dalam bidang bahasa dan kajian wacana, terutamanya dalam menunjukkan kehadiran aspek-aspek implikatur dalam penulisan warkah. Dapatan kajian ini juga diharapkan akan menambah kepada peluasan pengetahuan dalam penghasilan sesebuah teks secara umum, dan dalam penulisan warkah/surat-menyurat secara khusus.

\section{OBJEKTIF KAJIAN}

Objektif kajian ini ialah untuk:

1. Mengenal pasti implikatur yang terdapat dalam warkah koleksi peribadi Za'ba.

2. Menghurai dan menganalisis implikatur sebagai strategi kesopanan dalam warkah tersebut.

\section{SOROTAN KAJIAN LALU}

Kajian mengenai implikatur atau ketersiratan makna ujaran telah banyak dilakukan oleh pengkajipengkaji luar mahupun tempatan. Kajian ini pernah dilakukan di Malaysia oleh pengkaji-pengkaji seperti Nor Hashimah Jalaluddin (1991, 1992), Fatimah Subet (1999), Maimunah Ibrahim (1999), Mustafa Atan (2010), Nor Hashimah Jalaluddin (2012), Indirawati Zahid (2012), Amirah Ahmad \& Nor Hashimah Jalaluddin (2013), Wong Shia Ho (2014), Nor Afiqah Wan Mansor \& Nor Hashimah jalaluddin (2016) dan Fatin Rabiha Abdul Kadir \& Zaitul Azma Hamzah (2017), manakala antara pengkaji luar negara yang membincangkan implikatur ialah Salmon (2011), Mustafa (2010) dan Widiana (2014).

Nor Hashimah (1991) pada mulanya telah mengkaji mengenai aspek ketersiratan makna dan telah menggunakan konsep implikatur bagi menjelaskan ketersiratan makna ujaran orang Melayu yang menyampaikan mesej dengan cara yang paling sopan, iaitu berselindung di sebalik kata-kata yang manis walaupun mungkin perkara yang ingin disampaikan itu kurang menyenangkan. Nor Hashimah (1992) sekali lagi menjalankan kajian tentang implikatur dengan mengkaji bahasa yang digunakan sewaktu aktiviti perniagaan dalam kalangan orang Melayu. Hasil kajian beliau menunjukkan bahawa implikatur dapat membantu peniaga menambat hati pelanggan dan mereka akan berkunjung kembali membeli barangan jualan di premis tersebut, di samping dapat memberikan keuntungan kepada kedua-dua belah pihak, iaitu peniaga dan pelanggan.

Fatimah Subet (1999) pula telah mengkaji implikatur yang terdapat dalam pantun Melayu Sarawak. Beliau telah memberi tumpuan terhadap makna yang melangkaui makna literal atau makna yang tersurat dalam pantun dengan mengambil kira pengguna dan penggunaannya. Hasil kajian beliau bahawa terdapat sepuluh jenis strategi penggunaan implikatur digunakan dalam pantun Melayu Sarawak.

Mustafa Atan (2010) menghuraikan ketersiratan makna sesuatu ujaran dalam filem dengan menggunakan ujaran oleh watak-watak dalam filem seniman agung P. Ramlee sebagai data kajian. Hasil kajian telah membuktikan bahawa pengkajian bahasa dalam konteks ilmu pragmatik amat luas dan dapat diteroka dengan pelbagai bahan seperti filem. Mustafa Atan (2010), berpandangan bahawa makna sebenar ujaran yang berimplikatur dalam filem perlu dikaji dan dianalisis dengan lebih mendalam kerana keupayaan mentafsir setiap ujaran yang diucapkan oleh watak dapat membantu penonton dan pendengar memahami keseluruhan cerita dan mesej yang ingin disampaikan oleh pengarang.

Indirawati Zahid (2012) telah membincangkan kesantunan Melayu ke arah bebas konflik. Beliau telah menghuraikan aspek kesantunan bahasa dalam masyarakat dan fungsinya sebagai medium menjaga air muka pemeran yang terlibat. Dalam konteks implisit, beliau telah menggunakan lakuan bahasa tak langsung atau indirectness yang digunakan untuk menyampaikan maksud tertentu. Indirawati (2012) menyatakan bahawa ramai sarjana berpandangan sekiranya lebih implisitnya sesuatu lakuan bahasa, maka lebih dianggap santun lakuan bahasa tersebut. Kajian beliau dilihat sangat signifikan dengan keperluan aspek kesantunan berbahasa dalam masyarakat melalui penggunaan kata- 
kata yang implisit, selaras dengan situasi kesantunan bahasa dalam konteks menjaga air muka seseorang mutakhir kini yang menunjukkan gejala yang membimbangkan dalam media sosial seperti Facebook, Youtube dan Twitter.

Wong Shia Ho (2014) telah meneliti penggunaan simbol dalam teks ucapan Tunku Abdul Rahman bagi menonjolkan kebijaksanaan Tunku menggunakan simbol untuk menyampaikan mesej kepada pendengar. Simbol dalam konteks tersebut ialah objek yang bersifat maujud dan berada dalam pengetahuan sedia ada atau catatan ensklopedia pendengar. Menurut beliau, penggunaan objek dalam menyampaikan mesej ini dapat membantu pendengar menginterpretasi makna implisit yang ingin disampaikan. Hajil kajian menunjukkan bahawa penggunaan simbol dalam ujaran mampu diinterpretasi oleh pendengar sebagaimana yang diinginkan oleh Tunku.

Nur Afiqah \& Nor Hashimah Jalaluddin (2016) mengkaji tentang deria rasa masam, masin, manis dan pahit dalam kiasan orang Melayu. Beliau telah menghuraikan makna implisit dan makna implisit kompleks dalam bahasa kiasan khususnya peribahasa dan kaitannya dengan akal budi Melayu. Pengkaji telah mengaplikasikan teori semantik dengan kaedah inkuisif yang menggabungkan data, teori, kognitif dan falsafah sehingga membawa kepada tafsiran akal budi Melayu. Hasil kajian telah menunjukkan bahawa kiasan Melayu mempunyai kaitan yang rapat dengan budaya dan akal budi Melayu. Ketersiratan makna masam, manis, masin dan pahit serta makna yang berasosiasi dengan rasa dapat dicungkil dan dikaitkan dengan akal budi penuturnya.

Seterusnya, Fatin Rabiha dan Zaitul Azma (2017) pula telah mengkaji ujaran implisit dalam filem Melayu klasik Sri Mersing. Dalam kajian ini, pengkaji tersebut mengenal pasti ujaran yang terdapat dalam filem klasik 'Sri Mersing' dan menganalisis makna implisit dengan menggunakan teori relevans. Dapatan telah menunjukkan terdapat lima petikan ujaran dalam filem tersebut mempunyai makna implisist. Elemen implisit tersebut telah mendedahkan keperluan memahami ujaran yang disampaikan dengan menggunakan konteks dan kesan konteks. Dapatan kajian mereka juga telah menunjukkan pemahaman masyarakat terhadap penggunaan bahasa Melayu yang kaya dengan ujaran dan makna implisit. Selain itu, kajian ini juga dapat menonjolkan keindahan dan keunikan bahasa yang terdapat dalam filem Melayu tradisional terutamanya sekitar 60-an.

Antara kajian luar negara pula ialah kajian yang dilakukan oleh Salmon (2011). Beliau telah menghuraikan tentang kelas makna yang dikenali sebagai implikatur konvensional (CI), yang telah mendapat perhatian yang meluas dalam kesusateraan pragmatik dan semantik. Salmon (2011) telah mengkaji mengenai konsep-konsep yang wujud dalam implikatur konvensional yang berasaskan pandangan asal Grice (1975) dan penjelmaan semula konsep implikatur oleh Potts $(2005,2008)$. Hasil kajian mendapati terdapati perbezaan antara kedua-dua jenis implikatur konvensional walaupun terdapat komen bahawa perbezaan ini tidak selalu diakui dan beliau juga telah menggambarkan akan wujud masalah ketika ia berlaku.

Mustafa (2010) mengkaji perbezaan implikatur dalam kajian linguistik dan kewartawanan. Kajian beliau telah menunjukkan bahawa implikatur sebagai satu elemen penting dalam pragmatik yang menghubungkan jurang antara komunikasi secara literal dengan komunikasi secara sengaja. Implikatur juga memainkan peranan penting dalam merapatkan jurang budaya yang berbeza. Hasil kajian beliau menunjukkan implikatur boleh menjadi alat pemindahan budaya dan dapat dimanfaatkan sebagai rentas bidang bagi menghuraikan lingustik pragmatik dan bahasa media berfungsi.

Widiana (2014) telah menjalankan kajian pragmatik tentang jenaka dan implikatur dalam bidang penyiaran. Kajian beliau menggunakan kaedah persamaan pragmatik untuk menganalisis topik jenaka berdasarkan implikatur yang terkandung di dalamnya. Hasil kajian menunjukkan terdapat keduadua jenis implikatur konvensional dan perbualan di dalamya. Selain itu, implikatur dalam jenaka dapat dibahagikan berdasarkan jantina, budaya dan fenomena sosial. Dapatan kajian beliau juga menunjukkan implikatur dalam jenaka bukan sahaja dapat menghiburkan, malah dapat melembutkan kritikan atau satira agar tidak dianggap kasar.

Berdasarkan kajian-kajian di atas, pengkaji-pengkaji dalam negara telah memanfaatkan kajian mereka tentang penggunaan bahasa tidak berterus terang terhadap konteks dan budaya Melayu. Kebanyakan daripada pengkaji terdahulu menggunakan data daripada bahan-bahan sastera seperti pantun dan filem; selain daripada teks ucapan dan data daripada media sosial untuk menghuraikan makna tersirat dalam kajian mereka. Selain itu, pengkaji luar negara pula menggunakan data yang berbentuk hiburan dan data dalam bidang kewartawanan dan mendapati bahawa implikatur ini dapat 
meretas bidang. Dapatan kajian tersebut telah menunjukkan bahawa implikatur ini dapat dimanfaatkan dalam pelbagai bidang dan konteks. Oleh itu, kajian ini dihasilkan untuk menghuraikan penggunaan bahasa tidak langsung atau tidak berterus terang dalam koleksi warkah tokoh tersohor tanah air bagi menambah koleksi kajian yang telah sedia ada, di samping bagi mengenal pasti cara Za'ba dan peserta yang terlibat memanfaatkan penggunaan implikatur dalam peristiwa komunikasi tersebut iaitu, penulisan warkah.

\section{LATAR BELAKANG WARKAH KOLEKSI PERIBADI ZA’BA}

Koleksi warkah peribadi Za'ba boleh diakses di Arkib Negara Malaysia, Kuala Lumpur dengan kod panggilan SP17 dan Perpustakaan Peringatan Za'ba, Universiti Malaya. Dianggarkan sebanyak 3197 pucuk warkah tersimpan di Arkib Negara, manakala baki beratus-ratus pucuk lagi ditemui terselit dalam 3179 buah buku koleksi Za'ba yang telah diserahkan kepada Perpustakaan Peringatan Za'ba, Universiti Malaya.

Kebanyakan warkah yang ditemui ditulis menggunakan tulisan Jawi dan Rumi dan menggunakan laras bahasa Melayu Lama. Menurut Rashidah (2009), Za'ba sebenarnya amat suka menulis dengan menggunakan tulisan Jawi kerana pada pendapat beliau, sekiranya beliau menggunakan tulisan ini banyak cerita yang boleh ditulisnya (Rashidah, 2009, h.32). Selain itu, menurut Asmah (2008), Za'ba ialah orang yang pertama berusaha untuk memantapkan ejaan Jawi dan beliau telah menghasilkan buku yang bertajuk Rahsia Ejaan Jawi yang diterbitkan pada tahun 1929.

Selain daripada tulisan Jawi, terdapat juga warkah yang ditulis dengan menggunakan bahasa Inggeris. Sistem tulisan dalam warkah tersebut agak mudah dibaca. Walau bagaimanapun, disebabkan terdedah oleh perubahan masa, kebanyakan warkah beliau telah rosak dan kurang jelas. (Hashim Ismail, 1996).

Pengkaji telah menganalisis warkah-warkah yang dikumpul oleh Za'ba yang dikirim dan diterima beliau daripada saudara dan kenalan seperti bapa, adik-adik, serta anak-anaknya. Warkah-warkah ini ditemui sekitar tahun 1916 sehingga tahun 1973. Warkah ini diperoleh dalam simpanan Arkib Negara Malaysia, Kuala Lumpur. Antara isi kandungan warkah ialah untuk bertanya khabar, menjawab pertanyaan, memberi nasihat, ucapan bersimpati, memohon kebenaran dan memberi keizinan.

\section{METODOLOGI KAJIAN}

Kajian analisis teks ini berasaskan kaedah kualitatif. Kerangka kerja yang dicadangkan oleh Ary, Jacobs dan Razaveih (2002) telah digunakan untuk memproses dan menganalisis data kajian. Ary, Jacobs dan Razaveih (2002), menyatakan bahawa analisis kandungan atau analisis teks bermaksud satu strategi kajian yang digunakan untuk mengenal pasti ciri-ciri tertentu bahan-bahan yang dianalisis. Bahanbahan tersebut berkemungkinan dalam bentuk bahan bertulis atau visual, contohnya seperti buku, akhbar, rancangan televisyen dan sebagainya. Berdasarkan pandangan ini maka koleksi warkah peribadi amat sesuai dijadikan sebagai data dalam kajian yang bersifat kualitatif.

Cresswell (2012) telah menghuraikan mengenai data yang boleh dijadikan bahan dalam analisis kualitatif. Menurut beliau:

"Documents consist of public and private records that qualitative researchers obtain about a site or participants in a study, and they can include newspapers, minutes of meetings, personal journals, and letters. These sourses provide valuable information in helping researchers understand central phenomena in qualitative studies.'”(p.223)

Berdasarkan petikan ini, Cresswell (2012) berpandangan bahawa dokumen sama ada rekod awam atau swasta, serta akhbar, minit mesyuarat, jurnal peribadi boleh dijadikan bahan analisis kerana sumbersumber ini dapat memberi maklumat yang berharga dalam membantu pengkaji memahami fenomena kajian. Daripada huraian tersebut warkah peribadi sesuai untuk dijadikan sebagai bahan analisis bagi 
kajian yang bersifat kualitatif. Menurut Ary, Jacobs dan Razaveigh (2002), prosedur yang perlu dilalui oleh seseorang pengkaji yang ingin mengaplikasikan pendekatan ini ialah pengkaji perlu mengenal pasti fenomena kajian, kemudian pengkaji perlu memilih atau mengenal pasti bahan atau media yang dijadikan sebagai data, membentuk kategori koding, membuat persampelan, dan menganalisis data yang dikaji. Berdasarkan prosedur tersebut, didapati bahawa koleksi warkah peribadi sesuai untuk dijadikan bahan dalam menganalisis data mengikut tatacara yang digariskan.

Prosedur pertama yang dilakukan ialah, pengkaji mengumpul dan meneliti warkah peribadi pendeta Za'ba yang dikumpul oleh beliau dengan pelbagai topik. Seterusnya, pengkaji telah mentransliterasi warkah yang dikumpul daripada tulisan Jawi kepada Rumi kerana warkah tersebut ditulis dalam pelbagai bentuk sistem tulisan dan saiznya. Setelah selesai proses pengumpulan data, pengkaji telah menjalankan proses memeriksa korpus. Tujuan proses pemeriksaan korpus dijalankan adalah untuk mengenal pasti dan menentukan komponen implikatur yang terdapat dalam warkah tersebut. Seterusnya, data ini dianalisis dengan menggunakan pendekatan implikatur yang dihuraikan oleh Grice (1975) yang telah disesuaikan mengikut konteks budaya dan masyarakat Melayu oleh Asmah (1992) iaitu bebelit-belit, kiasan, berlawanan dan orang perantaraan.

\section{KERANGKA KAJIAN}

Menurut Raja Masittah Raja Arifin (1990), konsep implikatur yang digagaskan oleh Grice (1975) telah dibincangkan dalam sebuah kuliah William James Lectures (1967) di Universiti of Harvard yang berjudul Logic and Conversation (1975). Istilah ini kemudiannya telah disebarkan, lalu menjadi popular dan mendapat tempat dalam kalangan pengkaji-pengkaji bahasa sama ada di dalam mahupun di luar negara. Grice (1975) menghuraikan bahawa seseorang penutur perlu bertanggungjawab bagi memastikan implikatur disedari oleh pendengar, di samping dia dapat menginterpretasikannya. Beliau juga menyatakan bahawa apa yang dipentingkan dalam menentukan makna ialah tujuan sebenar penutur dan bukannya perkara yang dikatakan. Beliau juga telah membahagikan implikatur kepada implikatur konvensional dan implikatur perbualan. Konsep implikatur yang dicadangkan oleh Grice ini berkait rapat dengan prinsip kerjasama beliau, iaitu maksim kualiti, maksim kuantiti, maksim perhubungan dan maksim perlakuan/cara.

Dalam konteks masyarakat Melayu, implikatur digunakan oleh penutur sebagai medium untuk menyatakan suatu maksud sebenar dengan tujuan dan maksud yang tertentu, contohnya seperti menjaga hati atau air muka seseorang penutur di samping mewujudkan kesantunan berbahasa. Menurut Asmah (1992, p.175-186), implikatur yang hadir dalam peristiwa komunikasi dalam masyarakat Melayu dapat dibahagikan kepada empat kaedah, iaitu:

- Berbelit-belit

- Kiasan

- Berlawanan

- Orang perantaraan

Berbelit-belit membawa maksud penutur tidak menyatakan secara langsung apa yang diinginkan, tetapi telah membawa pendengar kepada perkara-perkara lain yang ada sedikit perkaitan dengan maksud yang ingin disampaikannya. Berdasarkan cara ini, penutur mengambil masa beberapa ketika untuk memperkatakan tentang perkara lain sebelum sampai kepada tujuan asal. Perkara lain yang diperkatakan oleh penutur tersebut boleh jadi berkaitan atau tidak dengan perkara yang ingin disampaikan.

Kiasan pula ialah ungkapan yang tidak berterus terang, tetapi dikiaskan dengan menggunakan perkara lain seperti unsur alam. Menurut Za'ba (2000), bahasa kiasan ialah cara seseorang individu menyatakan sesuatu perkara dengan mengkiaskan kepada perkara lain dengan bandingan atau tidak. Bahasa kiasan digunakan dengan tujuan bagi menambahkan kejelasan perkara yang dibincangkan atau diceritakan di samping memperkukuhkan maksudnya. 
Konsep berlawanan pula bermaksud penutur menggunakan kata-kata yang berlawanan dengan maksud yang ingin disampaikan dengan tujuan merendah diri atau berlaku sopan, manakala orang perantara pula ialah seseorang individu menggunakan orang ketiga sebagai perantara bagi menyampaikan sesuatu perkara oleh penutur merasa kurang yakin atau orang ketiga itu mempunyai kedudukan dalam masyarakat dan akan lebih diyakini kata-katanya. Kaedah-kaedah ini digunakan selalunya dengan tujuan berlaku sopan, seterusnya menjaga air muka dan memelihara keharmonian dalam peristiwa komunikasi.

\section{ANALISIS DAN PERBINCANGAN}

Mempraktikkan kesopanan ialah salah satu daripada cara bagi mewujudkan hubungan yang baik antara sesama individu, baik dalam budaya masyarakat Melayu mahupun kebanyakan budaya lain yang terdapat di dunia ini. Bagi mewujudkan suasana berkomunikasi yang sopan dan harmonis, kita perlu memahami tatacara atau teknik komunikasi yang telah digariskan dalam masyarakat tertentu. Masyarakat Melayu secara amnya telah merangka beberapa peraturan atau teknik berbahasa yang boleh atau tidak boleh dilakukan oleh anggota masyarakat sebagai panduan bagi mewujudkan suasana hubungan yang harmonis sesama individu. Peraturan-peraturan tersebut mengambil kira aspek sosiolinguistik dan pragmatik dan salah satu daripada komponennya ialah implikatur atau komunikasi tidak berterus terang.

Masyarakat Melayu telah menggunakan implikatur sebagai suatu cara bagi menyatakan suatu maksud sebenar dengan tujuan dan maksud yang tertentu seperti ingin menjaga hati atau air muka seseorang penutur di samping mewujudkan kesantunan berbahasa. Menurut Asmah (1992, p.175-186), implikatur yang digunakan sewaktu berlakunya komunikasi dalam masyarakat Melayu dapat dibahagikan kepada empat kaedah, iaitu berbelit-belit, kiasan, berlawanan dan orang perantaraan. Walau bagaimanapun, setelah diteliti, terdapat tiga kaedah implikatur yang digariskan oleh Asmah (1992) dalam data kajian, iaitu berbelit-belit, kiasan dan orang perantaraan.

\section{BERBELIT-BELIT}

Penggunaan berbelit-belit boleh dikaitkan dengan konsep implikatur dalam kajian lakuan bahasa. Perkataan implikatur telah dikemukakan oleh Grice (1975) yang menerangkan bahawa apa yang diperkatakan oleh penutur sebenarnya berbeza dengan yang dimaksudkannya. Dalam hal ini, Grice (1975: 43) telah memudahkan pengertian dengan memberikan contoh seperti berikut:

Suppose that $A$ and $B$ are talking about a mutual friends, $C$ who is now working in a bank. A asks B how is $C$ is getting on his job, and B replies,

\section{B: Oh quite well, I think, he likes his colleagues and he hasn't been to prison yet.}

Dalam komunikasi di atas, penutur B sebenarnya bercakap mengenai perkara berbeza daripada apa yang dimaksudkannya. Implikatur perbualan yang diperoleh daripada ujaran tersebut sebenarnya bergantung pada konteks perbualan ketika itu itu dan hanya difahami oleh kedua-dua penutur tersebut. Dalam hal ini, penutur B sebenarnya ingin memberitahu bahawa rakan mereka $\mathrm{C}$ telah berubah sikap dan tidak berlaku jujur dalam pekerjaannya. Selain itu, Nor Hashimah Jalaluddin (2003), menyatakan bahawa implikatur banyak melibatkan ketersiratan yang perlu disingkapkan maksud keseluruhannya.

Pantun Melayu juga menggunakan aspek berbelit-belit. Dalam pantun Melayu, terdapat dua rangkap pertama yang dikenali sebagai pembayang maksud, manakala rangkap seterusnya pula ialah maksud. Pembayang maksud pada dua rangkap pertama itulah yang mencerminkan aspek berbelit-belit, manakala mesej sebenarnya terletak pada dua rangkap akhir iaitu maksud. Contoh pantun seperti berikut: 


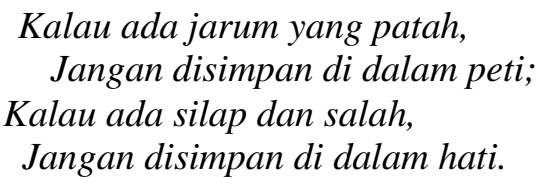

Pantun di atas menggunakan kaedah berbelit-belit dengan menggunakan pembayang maksud mengaitkan dengan jarum yang patah, sedangkan maksud sebenarnya ialah pemantun tersebut ialah supaya tidak menyimpan rasa marah atau kecil hati sekiranya dia melakukan kesalahan. Pemantun mengaitkan dengan jarum yang patah dan hati yang sakit kerana sifat jarum yang akan menyakitkan seseorang apabila tercucuknya, khususnya jarum yang sudah patah. Berdasarkan pantun ini dapat digambarkan bahawa sifat orang Melayu yang sangat mementingkan penggunaan aspek strategi komunikasi bagi menggambarkan kesopanan berbahasa dengan orang yang dilawan tutur.

Hasil analisis mendapati warkah koleksi pendeta Za'ba juga mempunyai unsur berbelit-belit. Unsur berbelit-belit ini ditulis bagi menyampaikan teguran meluahkan perasaan kepada penerima warkah. Contoh penggunaan unsur berbelit-belit dalam warkah Za'ba seperti berikut:

\begin{abstract}
"Ahwal ayahanda maklumkan warkah anakanda tarikh 13/7/19 sudah ayahanda terima. Apakala ayahanda buka daripada menerimanya demi terbaca sahaja oleh ayahanda tentang ---- yang maha bodoh terlebih daripada sebatang keldai itu. Terhibalah hati dan semangat ayahanda naik ke langit menyapunya awan-awan yang biru kemudian terhempas pula ke bumi dengan amat dahsyatnya serta berhamburan pecah belah umpama kaca jatuh ke batu. Hancur luluhlah dengan tiada dapat diperbaikilah."
\end{abstract}

(Tarikh: 17 Julai 1919)

Contoh:

"Maka, anakanda pun telah terkedu di hati selama ini iaitu jika pendek umur ayahanda maka biarlah diambilnya sekali harta benda ayahanda dan kampung halaman dan sekalian jarum-jarum patah ayahanda semuanya biarlah pulang kepadanya."

(Tarikh: 1 Disember 1912)

Contoh:

"Kriang! Bunyi pinggan pecah dalam satu dapur. Terdengar pula suara bertanya "Apa yang engkau pecahkan itu Aminah? Tidak emak, bukan saya pecahkan, kucing itu dilanggarnya pinggan yang atas meja itu. Lafaz Aminah. Yang sebetulnya Aminah yang memecahkan pinggan itu, tetapi oleh ia takut hendak bercakap benar, takut kena pukul dan lagi ia sudah biasa bercakap bohong dan terlepas daripada denda-denda yang patut, Aminah sudah sedap bercakap bohong."

(Tarikh: 13 September 1939)

Berdasarkan warkah yang ditulis pada tarikh 17 Julai 1919 ini, penulis warkah tersebut, iaitu ayahanda Za'ba merasa sangat kecewa apabila membaca warkah yang diterima oleh beliau. Kekecewaan dan kemarahan terhadap Za'ba ini dinyatakan secara berselindung tanpa memberitahu yang beliau sangat kecewa dengan tulisan Za'ba sebelum ini. Ungkapan terhibalah hati dan semangat ayahanda naik ke langit menyapunya awan-awan yang biru yang kemudiannya terhempas pula ke bumi menunjukkan kekecewaan yang terlampau oleh ayahandanya. Penggunaan kata-kata ini dilihat selaras dengan masyarakat Melayu pada zaman tersebut yang sering menyembunyikan kemarahan dan kekecewaan mereka walaupun kata-kata itu ditujukan kepada orang yang lebih muda daripada mereka. Walaupun 
warkah itu ditulis oleh seorang bapa kepada anaknya, namun dengan tujuan berlaku sopan beliau menggunakan strategi berbelit-belit supaya anak beliau tidak berkecil hati.

Warkah yang bertarikh 1 Disember 1912 juga mengaplikasikan kaedah berbelit-belit. Warkah ini ialah warkah yang dibalas oleh Za'ba kepada ayahandanya. ZA'BA merasa sangat sedih dan kecewa apabila menerima warkah daripada ayahandanya berkenaan ibu tirinya, bonda Wok. Puncak kesedihan dan kekecewaan beliau dinyatakan dengan ungkapan jika pendek umur ayahanda maka biarlah diambilnya sekali harta benda ayahanda dan kampung halaman dan sekalian jarum-jarum patah ayahanda semuanya biarlah pulang kepadanya yang bermaksud sekiranya ayah beliau telah tiada, tidak perlulah beliau meninggalkan harta pusaka kepada mereka adik-beradik dan lebih baik diberikan kepada ibu tirinya agar tidak berebut harta nanti. Beliau telah menggunakan bahasa yang halus dan tidak berterus terang agar ayahanda beliau tidak berkecil hati.

Pada tarikh 13 September 1939 Za'ba telah mengutus warkah kepada anaknya, bagi menasihatkan anak beliau supaya mendidik dan mengajar anak bercakap benar. Warkah ini dimulai dengan situsi suasana di dapur dan terdengar bunyi pinggan terhempas dan si anak tidak mengaku kesalahannya memecahkan pinggan tersebut, sebaliknya menuduh pula kucingnya yang berbuat demikian. Apabila selesai bercerita tentang situasi tersebut barulah beliau terus kepada tujuan sebenar penulisan warkah beliau. Berdasarkan perkara ini didapati bahawa Za'ba menggunakan cakap berlapik bagi menegur anak beliau tentang cara mendidik anak. Seterusnya, diharapkan apabila anak beliau membaca dan memahami kandungan warkah ini dia tidak merasa kecil hati dengan teguran tersebut.

Berdasarkan contoh-contoh di atas, didapati bahawa penulis-penulis warkah ini telah memanfaatkan kaedah berbelit-belit Asmah (1992) dalam warkah mereka. Mereka menggunakan kaedah berbelit-belit ini bagi menegur dan menyatakan rasa kecewa serta marah terhadap penerima surat. Walaupun mereka tida menyatakan secara berterus terang, namun sebagai masyarakat Melayu yang telah dididik dengan cakap berlapik ini sedikit sebanyak akan memahami perkara yang ingin disampaikan oleh penulis tersebut. Penggunaan kaedah berbelit-belit ini juga menyamai implikatur yang dihuraikan oleh Grice (1975).

\section{KIASAN}

Asmah (1992) mengaitkan kiasan dengan bayangan dan menyatakan bahawa lazimnya penutur memberikan bayangan sesuatu perkataan dengan keindahan alam semula jadi yang berada disekelilingnya. Za'ba (2000) telah menghuraikan kiasan ini dengan menyatakan bahawa selain bagi menjeskan maksud yang ingin disampaikan, kiasan juga digunakan untuk menmperindahkan ucapan atau tulisan kerana kiasan sering menggunakan kecantikan alam semula jadi dan perbandingan yang digunakan selalunya amat menarik. Kiasan juga dikenali sebagai 'bungaan bahasa' dan selalu digunakan untuk berselindung daripada maksud sebenar kerana perasaan malu atau tidak manis apabila didengar oleh orang lain.

Za'ba telah mengkelaskan kiasan kepada kiasan asal, kiasan berpindah, kiasan permanusiaan, kiasan berkacau, tamsil, ibarat, kias ibarat dan tamsil ibarat. Asmah (1992) berpendapat bahawa apabila kita bercakap tentang pantun, maka secara tidak langsung sebenarnya kita telah bercakap mengenai kiasan kerana di dalam pantun terdapat kiasan. Contohnya, pantun yang digunakan dalam majlis peminangan dan perkahwinan yang menggunakan kiasan seperti bunga yang sedang kembang di taman dan permata di dalam milik tuan sering digunakan bagi merujuk gadis yang hendak dipinang. Sehingga kini, kiasan dalam adat peminangan dan perkahwinan masih digunakan memeriahkan majlis tersebut kerana wakil kedua-dua belah pihak akan cuba untuk mencari pantun yang sesuai atau menyatakan kiasan terhadap sesuatu bagi menarik perhatian khalayak, sekaligus menceriakan suasana majlis tersebut.

Za'ba banyak menggunakan kiasan dalam penulisannya. Antara kiasan yang ditemui dalam warkah beliau ialah kiasan asal dan kiasan berpindah. 


\section{KIASAN ASAL}

Menurut Za'ba (2002), kiasan asal ialah yang menyebutkan bandingan yang terang-terang satu benda dibandingkan kepada satu benda dengan memakai seperti, seumpama, ibarat, laksana dan sebagainya dengan syarat kedua-dua benda yang hendak dibandingkan itu berlainan dan sama pada satu-satu perkara tertentu sahaja. Antara contoh kiasan asal yang terdapat dalam koleksi warkah ini seperti berhamburan pecah belah umpama kaca jatuh ke batu dalam warkah yang bertarikh 17 Julai 1919 yang menggunakan penada kiasan 'umpama' bagi mengkiasakan perasaan hati yang kecewa dengan kaca yang pecah.

Selain itu, terdapat juga kiasan asal pada warkah yang bertarikh 8 Ogos 1918 yang menyebut:

Terbakar kampung kelihatan asap terbakar, terbakar hati siapa yang tahu 2. Bagai kalah di tengah arus. Tidaklah dipanjangkan selama melainkan selama ayahanda dua laki isteri pada anakanda dua laki isteri.

(Tarikh: 8 Ogos 1918)

Warkah ini menggunakan penanda kiasan 'bagai' terhadap ungkapan bagai kalah ditengah arus bagi mengkiaskan kepada seseorang yang telah tewas atau mengalami kekalahan ditengah-tengah perjuangan. Berdasarkan contoh-contoh ini, kiasan asal digunakan bagi mengkiaskan maksud sebenar perkara yang ingin dinyatakan. Penulis warkah bijak memanipulasi penggunaan bahasa mereka supaya tidak menyinggung perasaan pembaca di samping berlaku sopan terhadap mereka.

\section{KIASAN BERPINDAH}

Kiasan berpindah juga ditemui dalam koleksi warkah ini. Kiasan berpindah bermaksud bahasa kiasan yang tidak menyebut bandingan, tetapi berpindah daripada perkara yang dimaksudkan kepada perkara yang dibandingkan. Kiasan berpindah yang hadir dalam koleksi warkah ini tergolong dalam kategori kiasan sandar, iaitu sesuatu perkara yang yang disandarkan kepada sesuatu benda yang lain sebagai kepunyaan benda tersebut.

Contoh penggunaan kiasan berpindah kiasan sandar ialah:

Tidak ada sebarang apa terima kasih yang anakanda hendak kembalikan kepada orang itu dan tidak ada anakanda terhutang budi barang sebesar hama pun kepadanya.

(Tarikh: 1 Disember 1912)

Si perempuan yang lemah itu tak sedar ke dunialah akan tak diketahuinya orang yang bermulut manis kepadanya itu berlidah ular-lidah bercabang-

(Tarikh: 13 September 1939)

Semuanya mulut manis tapi hati bersarang-sarang.

(Tarikh: 31 Mei 1919)

Dalam warkah yang bertarikh 1 Disember 1912 , ZA’BA mengkiaskan perasaan marah dan kecewanya terhadap sikap ibu tirinya ayat 'tidak terhutang budi barang sebesar hama pun kepadanya' bagi menunjukkan bahawa ibu tirinya tidak pernah berbuat baik terhadapnya. Ungkapan sebesar hama merujuk kepada perkara yang sangat kecil dan halus yang tidak boleh dilihat dengan mata kasar. Kiasan ini digunakan bagi tujuan berselindung daripada menggunakan bahasa yang kasar terhadap ayahanda beliau. 
Selain itu, dalam warkah yang bertarikh 13 September 1939 pula, ZA'BA menggunakan unsur kiasan bersandar 'berlidah ular - lidah bercabang' bagi menunjukkan kepada individu yang suka bercakap bohong. Masyarakat Melayu akan merujuk kepada orang yang suka berbohong sebagai lidah ular kerana ciri-ciri yang terdapat pada lidahnya yang bercabang dua yang bermaksud seseorang itu boleh menyatakan sesuatu perkara sama ada betul atau tidak.

Selain itu, dalam kategori kiasan berpindah, ditemui satu lagi jenis kiasan ini, iaitu kiasan berangkap. Kiasan berangkap daripada pertentangan bunyi sahaja di antara perkataanya dengan perkataan maksudnya yang sebenar yang dirangkapkan kepadanya (Za'ba, 2002). Contoh penggunaan kiasan berpindah berangkap dalam koleksi warkah ini seperti berikut:

Saya sedar sepenoh2-nya akan perkataan "ikut hati mati, ikut rasa binasa". wa'lhasil dalam perkara ini saya tidak mengikut fahaman "ulama yag banyak tentang memahamkan ajaran 'polygami' di dalam Islam.

(Tarikh: 8 April 1954)

Tetapi bila diam di Jempol terpaksa juga diikut kerana kita 'hidup dikandung adat dan mati dikandung tanah'.

(Tarikh: 29 Julai 1968)

Dalam warkah yang bertarikh 8 April 1954 pula, Za'ba menggunakan ungkapan yang berangkap 'ikut hati mati, ikut rasa binasa' kepada Che Mohamad Salleh Ashkar yang ingin berkahwin dengan anaknya, sedangkan beliau sudah mempunyai isteri. Dalam hal ini, beliau sebenarnya kurang bersetuju dengan keputusan mereka ingin berpoligami, tetapi menyatakan secara halus tentang ketidaksetujuan beliau. Walaupun beliau memberi keizinan kepada mereka untuk berkahwin, tetapi beliau menyuruh pasangan itu menangggung sendiri risiko yang berlaku. Kiasan berangkap seperti ini sering digunakan oleh masyarakat Melayu bagi menegur seseorang agar tidak terlalu mengikut perasaan kerana ia akan membinasakan diri mereka.

Selain itu, pada warkah yang bertarik 29 Julai 1968, Za'ba mengutus warkah Daniel dan Aini bagi menjawab pertanyaan mereka tentang adat pepatih. Beliau memberi jawapan bahawa beliau perlu mengikut adat tersebut kerana tempat tinggal beliau berpegang teguh dengan adat walaupun ada perkara-perkara yang tidak dipersetujui oleh belia. Konsep hidup dikandung adat dan mati dikandung tanah telah menjadi pegangan masyarakat pada ketika itu.

Berdasarkan contoh-contoh di atas, penulisan dalam koleksi warkah Za'ba ini banyak menggunakan kiasan berpindah dengan memihkan maksud ucapan kepada sesuatu perkara yang sifatnya hampir sama dengan perkara yang diperkatakan. Penggunaan kiasan ini bertepatan dengan huraian implikatur Asmah (1992) dan Grice (1975) yang menyatakan bahawa dalam implikatur seseorang individu akan bersandarkan kepada perkara yang lain bagi menyatakan maksud sebenar ucapannya.

\section{ORANG PERANTARAAN}

Menurut Asmah (1992), kaedah ini selalunya digunakan oleh penutur kepada orang yang dilawan tutur apabila terdapat perbezaan jurang dari segi status, umur dan sebagainya. Seseorang individu akan menggunakan perantara apabila dia merasakan terdapat suatu jarak antara dirinya dan penerima mesej. Jarak ini sekali gus akan menyebabkan perhubungan antara penyampai dan penerima mesej menjadi terbatas. Oleh itu, dia memerlukan satu pihak lain yang dirasakan mampu menyampaikan mesej tersebut. Contohnya, seorang pekerja bawahan yang ingin berjumpa dengan ketua pengarah syarikat, tetapi merasa rendah diri dan malu untuk berjumpa secara langsung, lalu meminta penyelia menaympaikan maksudnya. Dalam hal ini, penyelia menjadi perantara dalam peristiwa komunikasi tersebut. 
Hasil analisis mendapati bahawa warkah Za'ba menggunakan perantara. Dalam warkah ini, Za'ba sering dilantik sebagai perantara bagi mewakili rakan-rakan beliau memohon sesuatu tender, menulis ucapan selamat bercuti dan maju jaya dan juga menjadi wakil bagi salah seorang ahli keluarga beliau yang ingin memohon bekerja di Muzium Negara. Contoh warkah tersebut seperti berikut:

Bahawa tabik dengan beribu-ribu tabik daripada hamba yang hina bernama Zainal bin Ahmad serta Md. Nor dan Arshad bin Hj Mt Amin datang mengadap ka bawah kawan yang mulia M.P Weatheerspon Asist Engineer Rilway di dalam Kuala Pilah dalam beberapa selamatnya.

(Tarikh: 2 Novermber 1908)

Adalah kami sekalian guru-guru, penuntut-penuntut, kerani-kerani dan penterjemah-penterjemah di kolej ini dengan hormatnya melafazkan ucapan tidk sepertinya ini kepada tuan memberi selamat tuan bercuti pulang ke negeri tuan mengambil rehat serta berjumpa anak isteri dan kaum keluarga tuan dan lagi jika sebenarnya khabar menyatakan tuan tidak kembali semula berjawatan di Kolej selepas tuan bercuti itu maka kami ucapkan selamat belayar..

(Tarikh: 20 Julai 1939)

Saya di-minta oleh orang yang membawa warkah ini memperkenalkan diri kepada tuan. Namanya Mohd. Nor bin Shamsuri dan ia adalah menantu saudara kepada saya sendiri, berumur 30 tahun. Ia datang berjumpa tuan dengan hajat memohon kalau ada apa-apa kerja yang hendak pakai orang baharu dalam bahagian kakitangan pangkat jawatan rendah bagi membuat pekerjaan di muzium baharu ini.

(Tarikh: 18 Jun 1963)

Contoh-contoh kandungan warkah di atas menunjukkan Za'ba sebagai perantara dalam komunikasi tersebut. Za'ba mungkin dipilih sebagai wakil oleh rakan dan saudara beliau kerana pada masa tersebut beliau mempunyai kedudukan dalam masyarakat dan disegani oleh individu-individu tertentu kerana dalam masyarakat Melayu apabila seseorang individu yang ada kedudukan selalunya apa sahaja yang dihajati akan ditunaikan. Contohnya, dalam warkah yang bertarikh 2 November 1908, Za'ba menjadi perantara kawan-kawannya bagi memohon kontrak menebas hutan di sepanjang jalan kereta api Kuala Pilah. Begitu juga dalam surat yang bertarikh 18 Jun 1963, Za'ba telah mengutus warkah kepada Ketua Pengarah Muzium dengan tujuan membantu salah seorang daripada ahli keluarganya bekerja di Muzium Negara. Begitu juga dalam warkah yang bertarikh 20 Julai 1939, Za'ba menjadi perantara kakitangan dan pelajar bagi menyatakan ucapan selamat bercuti kepada pengetua Sultan Idris Training School. Za'ba telah menjadi perantara dalam ketiga-tiga situasi ini kerana kedudukan beliau dalam masyarakat pada masa itu yang dihormati dan disegani oleh semua.

Berdasarkan tiga jenis implikatur yang terdapat dalam warkah koleh $\mathrm{Za}$ 'ba ini, penggunaan implikatur dalam warkah-warkah ini telah mengambil kira semua aspek yang terdapat dalam masyarakat, iaitu sosiolinguistik, pragmatik dan budaya. Ketiga-tiga aspek ini mempunyai kaitan antara satu sama lain untuk menghasilkan komunikasi tidak langsung dalam masyarakat. Penggunaan implikatur dalam warkah Za'ba selaras dengan perlakuan masyarakat Melayu pada ketika itu yang menggunakan ungkapan tidak berterus terang dengan tujuan menjaga hati dan perasaan penerima warkah agar mereka tidak berkecil hati. Selain itu, penulis-penulis warkah tersebut juga bijak menyesuaikan penggunaan bahasa mereka dengan mengambil kira faktor siapa bercakap dengan siapa, di mana dan bagaimana penulisan itu dihasilkan, selaras dengan huraian Asmah (1992) dan Grice (1975). 


\section{KESIMPULAN}

Penulisan warkah koleksi Za'ba telah memanfaatkan tiga jenis implikatur iaitu berbelit-belit, kiasan dan perantara. Implikatur yang digunakan dalam koleksi warkah ini selari dengan budaya masyarakat Melayu yang pentingkan kesopanan berbahasa dan pertuturan dan perbuatan, sekali gus dapat memelihara air muka orang yang dilawan tutur. Kekuatan sesuatu implikatur banyak bergantung kepada sejauh mana maklumat tersirat yang disampaikan oleh seseorang individu itu mampu digapai oleh penerimanya tidak kira sama ada pembaca atau pendengar. Selain itu, bagi menjayakan sesuatu proses komunikasi, latar belakang konteks perlu diambil kira dan peserta tutur itu mesti memastikan bahawa dirinya telah menyediakan maklumat yang jelas yang mampu ditafsir oleh penerimanya. Secara keseluruhannya, dalam konteks penulisan warkah koleksi peribadi Za'ba ini, implikatur yang yang diungkapkan mampu digapai oleh penerimanya kerana inilah cara berkomunikasi masyarakat pada masa tersebut yang secara keseluruhannya tidak menyatakan sesuatu secara tidak berterus terang, tetapi digantikan dengan ungkapan yang lain bagi menjaga adab sopan serta tatasusila komunikasi tersebut terutamanya apabila berkomunikasi dengan individu-individu yang tertentu.

\section{RUJUKAN}

Ary, D., Jacobs, C.C., \& Razaveih, A. (2002). Introduction to research in education (6 ${ }^{\text {th }}$ ed.). California: Wadsworth / Thompson Learning.

Asmah Haji Omar. (2008). Ensiklopedia bahasa Melayu. Kuala Lumpur: Dewan Bahasa dan Pustaka.

Asmah Haji Omar. (2002). Setia dan santun bahasa. Kuala Lumpur: Dewan Bahasa dan Pustaka.

Asmah Haji Omar. (1992). The linguistic scenery in Malaysia. Kuala Lumpur: Dewan Bahasa dan Pustaka.

Cresswell, J.W. (2012). Educational research: Planning, conducting, and evaluating quantitative and qualitative research (4th ed). California: SAGE Publication.

Fatimah Subet. (1999). Implikatur dalam pantun Melayu Sarawak. Kuala Lumpur: Fakulti Bahasa dan Linguistik Universiti Malaya.

Fatin Rabiha Abdul Kadir \& Zaitul Azma Hamzah. (2017). Ujaran Implisit dalam filem Melayu Klasik Sri Mersing. International Journal of Language, Education and Applied Linguistics (IJLEAL), 6, 13-24.

Grise, H.P. (1975). Logic and Conversation. In P. Cole, \& J.L. Morgan (Eds.) Syntax and semantics 3: Speech Acts. New York: Academic Press.

Hashim Ismail. (1996). Warkah peribadi Za’ba kepada Mohd. Yusof Ahmad (1965-1973): Koleksi Perpustakaan Za'ba, dalam Wan Abdul kadir (Ed.). 100 tahun Za'ba, Za'ba: Pejuang bangsa. Kuala Lumpur: Akademi Pengajian Melayu, Universiti Malaya. 99-112.

Horn, L.R. (2004). The handbook of pragmatics. Blackwell: Oxford.

Indirawati Zahid. (2012). Kesantunan Melayu ke arah situasi bebas konflik. Dlm. Marlyna Maros, Mohd. Fadzeli Jaafar, \& Maslida Yusof. (Peny). Prinsip dan aplikasi kesantunan berbahasa, 170-189. Kuala Lumpur: Dewan Bahasa dan Pustaka.

Mustafa Atan. (2010). Implikatur dalam filem Tan Sri P.Ramlee. Tesis PhD, Universiti Putra Malaysia.

Mustafa Shazali Mustafa. (2010). The interpretation of implicature: A comparative study between implicature in linguistic and journalism. Journal of Language, Teaching and Research, 1(1), 35-43.

Nazri Atoh \& Zubir Idris. (2013). Simile sebagai kesantunan berbahasa dalam syair Siti Zubaidah. Jurnal Pendeta, 4 (1). 78-95.

Norazlina Hj.Mohd. Kiram \& Raja Masittah Raja Arifin. (2012). Kesantunan berbahasa orang Melayu menerusi Gaya pengurusan air muka dalam SAGA: Aplikasi teori Ting-Tomey. Jurnal Bahasa, 12(12), 284-300)

Nor Hashimah Jalaluddin. (1991). Keimplisitan ujaran: Satu analisis teori relevans. Jurnal Dewan Bahasa. 47483.

Nor Hashimah Jalaluddin. (2003). Bahasa dalam perniagaan: Satu analisis semantik dan pragmatik. Kuala Lumpur: Dewan Bahasa dan Pustaka.

Nor Hashimah Jalaluddin. (1992). Semantik dan pragmatik: Suatu pengenalan. Kuala Lumpur: Dewan Bahasa dan Pustaka.

Nur Afiqah Wan Mansor, \& Nor Hashimah Jalaluddin. (2016). Makna implisit bahasa kiasan Melayu: mempertalikan komunikasi, kognisi dan semantik. Jurnal komunikasi,32 (1), 189-206.

Raja Masittah Raja Arifin. (1990). J.R Searle, Jurnal Dewan Bahasa, 473-477.

Rashidah Ismail. (2009). Memoir Rashidah Ismail: Pendeta Za'ba dan kenangan silam. Bangi: Penerbit Universiti Kebangsaan Malaysia. 
Rohaidah Mahshudi, Abdul Mahmood Musanif, Adi Yasran Abdul Aziz, \& Hasnah Mohamad. (2013). Faktor kesopanan dan strategi komunikasi dalam genre perbincangan di televisyen. GEMA online Journal of Language studies, 13 (3), 163-178.

Salmon, W. (2011). Conventional implicature, presupposition and the meaning of must. Journal of Pragmatic, 43 (14), 3416-3430.

Sara Beden \& Indirawati Zahid. (2015). Pemetaan struktur peristiwa kesopanan berbahasa: Kombinasi model Leech (1983) dan Grice (1975). Jurnal Pendeta, 6 (1), 41-71.

Searle, J.R. (1975). Indirect Speech Acts, pp. 59-82, in: Cole, Peter \& Jerry L. Morgan (Eds). Syntax and semantics, Vol. 3: Speech act. New York: Academic Press.

Widiana, Y. (2014). A pragmatic study on jokes and the implicature in broadcast messages. World Academy of Sciences, Engineering and Technology International Journal of Humanities and Social Sciences, 8 (9), 1-14.

Wong Shia Ho. (2014). Penggunaan simbol dalam teks ucapan Tunku Abdul Rahman: Analisis teori relevans. Jurnal Bahasa, 14 (1), 60-92.

Zainal Abidin bin Ahmad (ZA’BA). (2000). Pelita bahasa Melayu I, II, III. Kuala Lumpur: Dewan Bahasa dan Pustaka.

Zainal Abidin bin Ahmad (ZA’BA). (2002). Ilmu mengarang Melayu. Kuala Lumpur: Dewan Bahasa dan Pustaka. 